\title{
Tipologías de la animación sociocultural
}

La acción asistencial, aunque de capital importancia, acumula muchos términos negativos en relación con la cultural y la socio. cultural (o psico-social). En vez de crear, reproduce; relaciona a benefactores con beneficiarios de forma vertical; ofrece servicios en lugar de "autoservicion; tiene como función uatestarn (legitimar y reforzar) al sistema social y no ucontestarlon (interpelarlo críticamente)

\section{Por Paloma LOPEZ DE CEBALLOS*}

\section{LOS ESQUEMAS DE PARTIDA}

En Formación de animadores y dinámicas de la animación (Paloma López de Ceballos y María Salas Larrazabal, Ed. Popular, Madrid 1987, 206 p.) aparecen dos esquemas para analizar la animación sociocultural, y la formación correspondiente: "Acción cultural, sociocultural y asistencial" y "Tiempos y destinatarios". Recordemos que el libro presenta una investigación, encargada por el Ministerio de Cultura, sobre los 51 Centros de Formación de Animadores existentes en España en ese momento. El trabajo recoge los resultados obtenidos por medio de un cuestinario de 133 uitems" tabulables por computadora y de 18 entrevistas en profundidad a directores y equipos de Centros representativos.

\section{Las tres Acciones}

El esquema inicial es de Joaquim Franc y Edouard Delgado. Con algunas modificaciones, da la tipología siguiente:

* Doctora en Sociologia por la Escuela de Altos Estudios de La Sorbona (Paris). Miemgro del Equipo del Centro de Investigación y Acción Cultural (CIAC). 


\section{Paloma López de Ceballos}

\begin{tabular}{|c|c|c|c|}
\hline $\begin{array}{l}\text { Tipos / } \\
\text { Caracteristicas }\end{array}$ & $\begin{array}{l}\text { Acción } \\
\text { Cultural }\end{array}$ & $\begin{array}{l}\text { Acción } \\
\text { Sociocultural }\end{array}$ & $\begin{array}{l}\text { Acción } \\
\text { Asistencial }\end{array}$ \\
\hline $\begin{array}{l}\text { Objetivo } \\
\text { básico }\end{array}$ & $\begin{array}{l}\text { Creación y } \\
\text { difusión corres- } \\
\text { pondiente }\end{array}$ & $\begin{array}{l}\text { Expresión y } \\
\text { encuentro }\end{array}$ & $\begin{array}{l}\text { Compensación, } \\
\text { terapéutica, } \\
\text { ayuda }\end{array}$ \\
\hline $\begin{array}{l}\text { Sirve a la } \\
\text { interpretación } \\
\text { de }\end{array}$ & $\begin{array}{l}\text { La experiencia } \\
\text { de la } \\
\text { humanidad. }\end{array}$ & $\begin{array}{l}\text { La experiencia } \\
\text { cotidiana. }\end{array}$ & La necesidad. \\
\hline Elabora & La sensi' l'inat & La identidad. & La demanda. \\
\hline $\begin{array}{l}\text { Genera primor- } \\
\text { dialmente. }\end{array}$ & $\begin{array}{l}\text { Símbolos. } \\
\text { Crea. }\end{array}$ & $\begin{array}{l}\text { Solidaridades } \\
\text { e identifica. } \\
\text { ciones. } \\
\text { Crea y recrea. }\end{array}$ & $\begin{array}{l}\text { Integración } \\
\text { social. } \\
\text { Recrea y } \\
\text { reproduce. }\end{array}$ \\
\hline $\begin{array}{l}\text { Establece } \\
\text { comunica- } \\
\text { ciones entre }\end{array}$ & $\begin{array}{l}\text { Expertos y } \\
\text { pone en } \\
\text { relación obra y } \\
\text { público. }\end{array}$ & $\begin{array}{l}\text { Individuos y } \\
\text { grupos. } \\
\text { Relaciones } \\
\text { horiles. }\end{array}$ & $\begin{array}{l}\text { Benefactores y } \\
\text { beneficiarios. } \\
\text { Relaciones } \\
\text { verticales. }\end{array}$ \\
\hline $\begin{array}{l}\text { Requiere infra- } \\
\text { estructuras de }\end{array}$ & $\begin{array}{l}\text { Creación y } \\
\text { difusión. }\end{array}$ & $\begin{array}{l}\text { Difusion y } \\
\text { encuentro. }\end{array}$ & $\begin{array}{l}\text { Ayuda y } \\
\text { transmision. }\end{array}$ \\
\hline Se produce en & $\begin{array}{l}\text { Viveros } \\
\text { artisticos. }\end{array}$ & $\begin{array}{l}\text { Asociaciones y } \\
\text { redes relación. }\end{array}$ & $\begin{array}{l}\text { Centros de } \\
\text { ayuda para la } \\
\text { marginalidad. }\end{array}$ \\
\hline Cataliza & Un autoservicio & $\begin{array}{l}\text { Servicio y auto- } \\
\text { servicio }\end{array}$ & Servictos \\
\hline Función social. & $\begin{array}{l}\text { Atestación o } \\
\text { contestación. }\end{array}$ & $\begin{array}{l}\text { Atestación o } \\
\text { contextación. }\end{array}$ & $\begin{array}{l}\text { Atestación de la } \\
\text { socledad. }\end{array}$ \\
\hline
\end{tabular}

Resumimos los comentarios del libro:

La formación de animadores en España se sitúa generalmente «a caballon entre la socio-cultural y la socio-asistencial, con mayor peso de la segunda. Solamente se situan predominantemente en la animación socio-cultural (tal como la caracteriza el esquema) seis Centros, y en la animación cultural dos.

Cada tipo de animación tiene su vocabulario privilegiado: 


\section{Tipologias de la animación sociocultural}

* Los promotores de la animación cultural hablan de museos, bibliotecas, festivales, televisión, vídeo, fotografía, cine, recitales y exposiciones.

* Los promotores de la animación socio-cultural recalcan en cambio los términos de grupo, relaciones, tejido social, asociaciones y solidaridad.

* Los promotores de la animación socio-asistencial hablan de cliente, necesidades, ayuda, demanda, terapia, integración y servicios.

Esos tres tipos de animación tienen ideologias y metodologías variadas que los subdividen a su vez. Por ello, nos encontramos en la práctica ante ocho modelos.

1. El tipo cultural responde a tres:

* Difusión cultural.

* Creación cultural-mecenazgo: Ayuntamientos, Centros de Formación o Fundaciones apoyan a artistas en conciertos, exposiciones o recitales. Es el más frecuente de los tres.

* Creación cultural comunitarla, con sus técnicas correspondientes.

2. El tipo socio-cultural que emerge puede ser:

- Directivo (muy frecuente); formadores de animadores y animadores optan por los progresos que debe realizar un grupo. Se sitúan "encima" de él.

* No directivo. El animador refuerza al grupo fundiéndose con él. Se sitúa uadentron, de manera a-crítica.

* Dialógica. El animador aprende a potenciar selectivamente desarrollos y dinamizaciones endógenas. Se sitúa en un proceso de identificación y distanciación crítica.

3. El tipo socio-asistencial responde a dos visiones contrapuestas:

* Paternalista, representado en el esquema, y que parece ser la más frecuente.

* Rogeriana, basada en la escucha activa, para que el interlocutor desarrolle sus capacidades de autonomía. 


\section{Paloma López de Ceballos}

\section{Tiempos y destinatarios}

El cltado libro aportaba otro esquema clasificatorio, en función de las edades de los destinatarios de la animación y del utiempon en que ésta se desarrolla.

\begin{tabular}{|l|c|c|c|c|c|}
\hline $\begin{array}{c}\text { Destinatarios } \\
\text { Tiempos }\end{array}$ & Ocio & $\begin{array}{c}\text { Tiempo } \\
\text { Libre }\end{array}$ & Paro & $\begin{array}{c}\text { Asociaciones/ } \\
\text { Voluntariado }\end{array}$ & Trabajo \\
\hline Niños & & 32 & & & \\
\hline Jóvenes & & 37 & 11 & & \\
\hline Adultos & & & & 10 & \\
\hline $3^{3}$ Edad & & 3 & & 1 & \\
\hline
\end{tabular}

Si se totalizan las cifras, hay más de 51 , que era el número de Centros encuestados, porque algunos de ellos se dedican a varias actividades destinadas a públicos diversos. El grueso de la animación se sitúa sin embargo claramente en niños y jovenes durante el tiempo
libre.

La casilla "ocion está completamente vacía porque animadores y Centros de Formación dicen con orgullo que han pasado del Aire Libre a) Tiempo Libre, "que es tiempo para educar". Sin embargo, esto no es asi en todos los casos. Hay muchas clases de rock, de cerámica, de elaboración de comics, de yoga, de balle... Se podría avanzar hacia una sinceración de la situación. Es más, ocio podria convertirse en un concepto positivo y podria hasta desarrollarse la profesión de "recreólogo", muy de moda en los palses anglosajones y que se dedica a llenar de manera especializada las demandas de sectores particulares de la población. España tiene, además, una tradición festiva y recreativa, con vínculos sociales espontáneos y un riquísimo folcklore que hay que cuidar y desarrollar.

En cuanto al Tiempo Libre, aunque el término aparece como más positivo que ocio para los encuestados, su significado no es demasiado preciso. Un entrevistado lo señala: el uleisure" inglés, "loisir", francés, o "lliure" catalán, son mucho más precisos y se enuncian en una sola palabra, traducida (iy traicionada?) por dos en castellano.

La atención al paro está creciendo, especialmente en lo que respecta a «óvenes en paron, debido a la ayuda del INEM que cubre 


\section{Tipologias de la animación sociocultural}

hasta los 25 años. Si disminuyese el paro juvenil y/o el INEM extendiese su ayuda a los de más de 25 años, la casilla radultos en paron crecería por lo menos al mismo ritmo, dado el problema nacional que representa la situación laboral actual.

También la categoria de asociaciones y voluntariado está creciendo, aunque en menor grado que la de jóvenes en paro. Dicho crecimiento se debe a las ayudas de la Dirección General de Acción Social y a la ideología especifica de una serie de Centros de Animación.

Además de la del ocio, otra casilla completamente vacia es la del trabajo. Añadamos que en este caso no hay un término sustitutivo, como con ocio-tiempo libre.

\section{Puesta en perspectiva}

Al querer sintetizar los dos esquemas aparece una contradicción no explicitada. Claramente, la formación impartida tiene por principal objeto el tiempo libre de jóvenes y niños. Sin embargo, la animación de la que se habla está a caballo entre la acción socio-cultural y la asistencial. Dado que la acción asistencial no se dirige al tiempo libre de niños y jóvenes ¿de dónde viene el desfase?

Tres hipótesis complementarias:

1. El trabajo que se ofrece a los genéricamente llamados "animadores" incluye importantes aspectos asistenciales, para la drogadicción, las prisiones, centros hispitalarios de la $3^{\mathrm{a}}$ edad, etc.

2. Muchos trabajadores sociales desempeñan trabajos de animación, a la que aportan su propia formación.

3. Aunque en el 87 los Centros de Formación de Animadores no solian tomar la acción asistencial como finalidad principal, se organizan cada vez más cursos monográficos sobre el tema.

En todo caso, vemos claramente que la animación en España se sitúa a nivel micro social y está mucho más ligada al ocio que al mundo del trabajo.

\section{Reflexiones criticas}

La animación parece a mucha gente "profusa, confusa y difusa". Ello se explica porque es un concepto rico en matices. Dar/reforzar 


\section{Paloma López de Ceballos}

el "animan de individuos, grupos y comarcas se traduce en todas serie de tareas: desde la animación de reuniones hasta la animación turistica, deportiva o carcelarial. Hay que continuar aclarando y ordenando nuestros enfoques metodológicos.

Además, el análisis de las tres Acciones parece indicar que «ni son todas las que están ni están todas las que sonn. Vamos, pues, a reflexionar sobre ellas.

\section{El polo cultural}

En Francia, los polos social y cultural se están separando y podrian llegar a constituir dos profesiones distintas: animadores culturales y animadores sociales.

El polo cultural por si solo bastaria para dar origen a otra tipologia. Cubre la creación y la difusión cultural y ambas pueden subdividirse: creación individual/colectiva; difusión de música/pintura/teatro; en ámbitos rurales/urbanos; para públicos jóvenes/adultos/3a edad; etc.

La labor queda por hacer.

\section{Un enfoque psico-social}

La "acción socio-cultural» descrita en el libro (la que se da con más frecuencia en la realidad española) no parece tanto "social" como "psico-social». Se dirige fundamentalmente a individuos, grupos y asociaciones, y no a lograr desarrollos comarcales endógenos.

Este enfoque psico-social seguirá cobrando auge, entre otras cosas porque los Ayuntamientos, Diputaciones y Autonomias se están convirtiendo en contratantes principales, no ya de animadores sino de empresas (cooperativas, Sales, Ltdas.) de animación. $Y$ entre éstas el enfoque psico-social está en boga.

\section{Animación y educación de adultos}

Aunque en el citado libro escribiamos que «la animación socio. educativa que hemos visto era más bien un vector hacia la acción socio-cultural y/o asistencial", posteriormente una serie de colectivos dedicados a la educación de adultos nos han explicado que lo que hacen es "animación».

Ambos enfoques deberian ser complementarios: no hay animación sin formación, y la formación integral incluye animación. Sin embargo, 
Tipologias de la animación sociocultural

para considerar "animación" a acciones concretas de educación de adultos hay un requisito indispensable: que la formación no esté prefabricada en base a asignaturas y niveles sino centrada en el autoaprendizaje asistido de los conocimientos, actitudes y destrezas requeridos por proyectos endógenos. Un ejemplo: el sistema NEB (necesidades educativas básicas) de la UNESCO, si era animación: los campesinos decidian lo que querian hacer (un pozo o una cooperativa) $y$, para ello, lo que necesitaban aprender.

\section{Región, empleo y calidad de vida, o la necesidad del enfoque global}

Aunque todos los tipos de animación que estamos describiendo son válidos, queremos subrayar la importancia de este enfoque, como lo haremos con el siguiente, por ser nuevos en la tipología.

Tres razones hacen deseable el apoyo de los poderes públicos a este tipo de animación. Ya la CEE lo está impulsando.

* El costo social del Acta Unica Europea puede ser altísimo para algunos sectores si no se refuerzan ante el previsible choque. Un fenómeno clásico en situaciones de colonización económica (y politica) es que las ocmunidades más débiles se debilitan aún más (pueden llegar hasta desaparecer) al encontrarse con otras más fuertes.

* Nuestro índice de paro (el más alto de la Comunidad) requiere la creación de riquezas y trabajo. "Animación = organización del ocion (aunque esto también es importante) resulta una falacia dañina en muchos ámbitos.

* La ecología es capital en animación, como debería serlo en múltiples tareas/profesiones. Baste evocar la desertificación, la quema de bosques, la capa de ozono...

Por todo ello, una animación socio-económica dirigida a la Acción Integral Rural/Urbana resulta importantísima, y exige un enfoque global. Muy a menudo se planifica a partir de una persona o grupo de personas, que entran en grupos o los crean, y se piensa que éstos se insertarán naturalmente en las dinámicas comarcales o autonómicas. La Acción integral procede al revés: toma al colectivo o región en su totalidad, identifica sus asociaciones más dinámicas y luego a las personas con mayor potencial. Ello requiere un tratamiento pluridisciplinario y articular los niveles macro y micro sociales, 


\section{Paloma López de Coballos}

importantes tareas (junto con la investigación) que tenemos por delante.

\section{Las carencias de lo asistencial}

La acción asistencial descrita acumula muchos términos negativos en relación con la cultural y la socio-cultural (o psico-social). En vez de crear, reproduce; relaciona a benefactores con beneficiarios de forma vertical; ofrece servicios en lugar de uauto-servicion; tiene como función "atestar" (legitimar y reforzar) al sistema social y no "contestarlo" (interpelarlo criticamente). En resumen, resulta "paternalista" y "asistencialista", como su nombre indica.

Sin embargo, no cabe rechazar sin más to asistencial, que es de capital importancia. La negatividad evocada no está en el campo asistencial en sí sino en el tratamiento otorgado. La animación de un colectivo de paraplégicos, por dar sólo un ejemplo, no tiene por qué ser «atestatarian de la sociedad existente, cuando, precisamente, debe criticar la falta de rampas, las carencias de la ortopedia, etc.

El error consiste en tomar a los "asistidos" como individuos aislados y establecer con ellos una relación vertical que los convierte en wobjetosn de cuidados. Una asistencia que implica a los colectivos correspondientes, los trata como sujetos y promueve enfoques globales de los problemas que los afectan, es verdadera animación. Pasa así de meramente asistencial a socioterapéutica.

\section{NUEVA TIPOLOGIA}

La necesidad de elaborar una nueva tipologia ha surgido de todo lo anterior. Está compuesta por cinco tipos de animación, en vez de tres. (La animación cultural no ha sido separada y desglosada).

La nueva tipología tiene también otras caracteristicas tipificadoras. Las "tres Acciones" tenían nueve características, sintetizadas ahora en cinco categorlas, tras suprimir la "Función social: atestación/contestación no están ligadas al tipo de animación sino a la finalidad de los promotores. Es dificil, por ejemplo, que una institución (ayuntamiento, hospital, etc.) se critique a si misma.

En cambio, se han añadido dos caracteristicas: los animadores privilegiados y la formación especifica. La primera de ellas, porque la profesionalización de la animación pasa por la doble especialización (en términos de formación, no de utitulitis»): economia/sociologia/ingenieria/medicina etc. y animación. 
Tipologias de la animación sociocultural

\begin{tabular}{|c|c|c|c|c|c|c|c|}
\hline 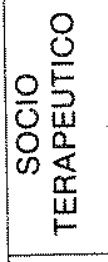 & 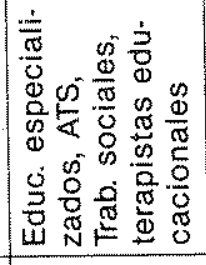 & 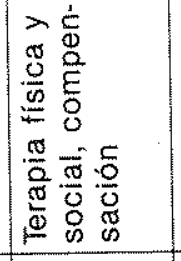 & 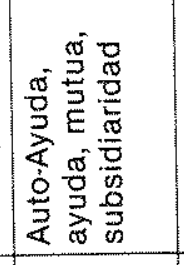 & 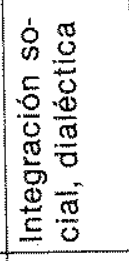 & 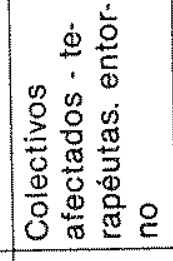 & 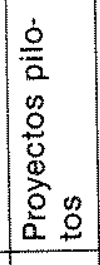 & 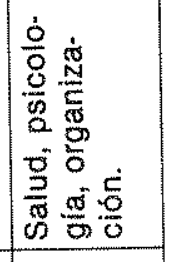 \\
\hline $\mid \begin{array}{l}0 \\
0 \\
0 \\
0 \\
0 \\
0 \\
0 \\
0 \\
0 \\
y\end{array}$ & 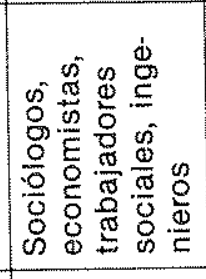 & 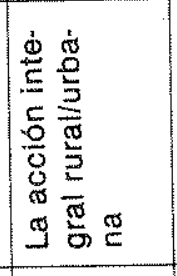 & \begin{tabular}{|l|}
$\frac{\pi}{5}$ \\
3 \\
0 \\
0 \\
0 \\
$\frac{\pi}{0}$ \\
$\frac{1}{0}$ \\
0 \\
\end{tabular} & 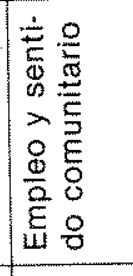 & 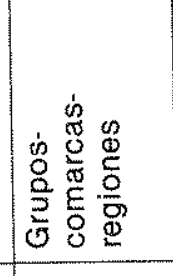 & 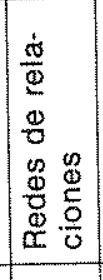 & 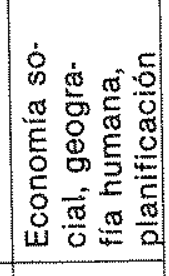 \\
\hline 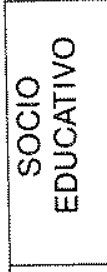 & 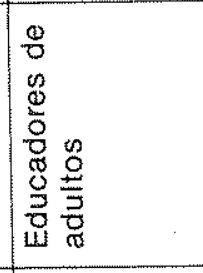 & 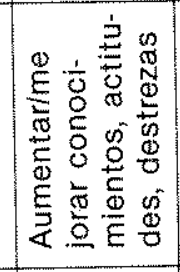 & 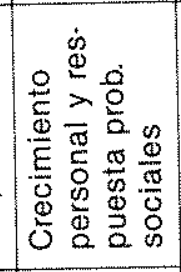 & 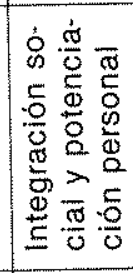 & 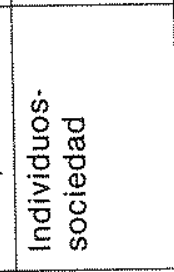 & 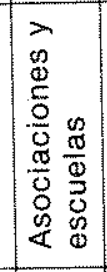 & $\begin{array}{l}\frac{\pi}{0} \\
0 \\
\frac{8}{8} \\
\frac{\pi}{0} \\
0 \\
0 \\
\end{array}$ \\
\hline $\begin{array}{l}8 \frac{1}{4} \\
\frac{8}{0} \\
0\end{array}$ & 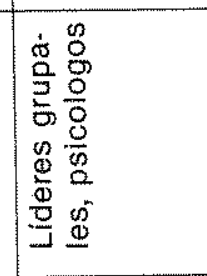 & 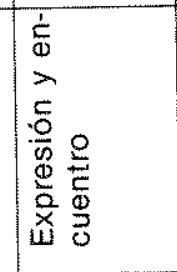 & 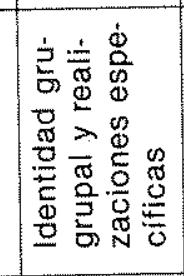 & 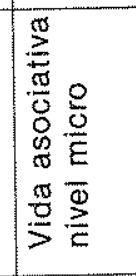 & 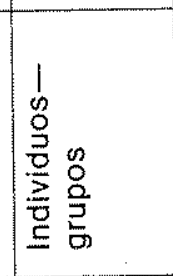 & 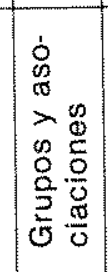 & 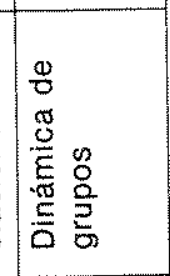 \\
\hline $\begin{array}{l}\frac{2}{\alpha} \\
\frac{a}{2} \\
\frac{5}{3} \\
0\end{array}$ & $\begin{array}{l}\frac{1}{3} \\
\frac{3}{00} \\
\frac{0}{5} \\
\end{array}$ & 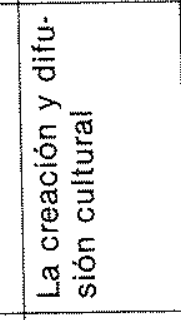 & 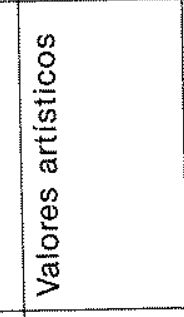 & $\begin{array}{l}0 \\
0 \\
8 \\
8 \\
\\
\\
0\end{array}$ & 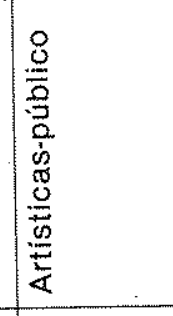 & 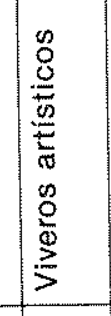 & 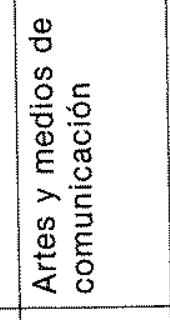 \\
\hline 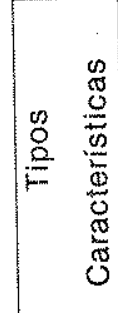 & 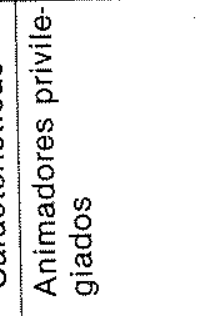 & 总 & $\frac{\mathfrak{d}}{\stackrel{9}{2}}$ & 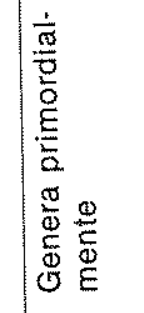 & 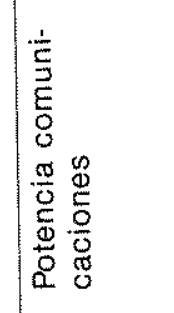 & $\begin{array}{l}5 \\
0 \\
0 \\
0 \\
0 \\
0 \\
0 \\
0 \\
0 \\
0 \\
0\end{array}$ & 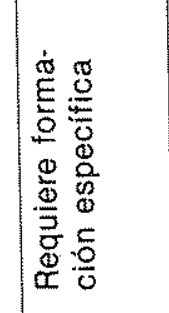 \\
\hline
\end{tabular}




\section{Paloma López de Ceballos}

Los tipos se complementan, Una Acción Integral Rural/Urbana del tipo socio-económico debe integrar importantes aportaciones del socio-terapéutico, además de aspectos del psico-social y del socioeducativo, y asi sucesivamente.

Pero, para combinar los tipos, hay que distinguirlos. Una vez aclarado el principal que se persigue, podemos elaborar proyectos de acción y de formación cada vez más coherentes.

Madrid, $14-4-89$ 